\title{
Research on The Assessment Systems for Student Cadres in Colleges*
}

\author{
Jun Yang \\ School of Computer Science and Technology \\ Shandong Technology and Business University \\ Yantai, China
}

\begin{abstract}
Student cadres are main helpers for the student education management in colleges, and the scientific performance assessment on student cadres can greatly promote the education management level in colleges. This article analyzes, studies and borrows the theories and methods relative to $\mathrm{HR}$ performance assessment, with the $\mathbf{3 6 0}$ degree feedback assessment method, it strives to explore scientific and rational methods and ways for the student carder performance assessment in colleges, which will do good to promoting the construction of student cadre teams.
\end{abstract}

Keywords—student cadres; performance assessment system; 360 degree assessment system; HR management

\section{INTRODUCTION}

Student cadres are implementers, organizers and managers of education management in colleges, in order to strengthen the construction of student cadre teams, it needs to establish not only standard and rational systems but also student cadres performance assessment system so as to gradually realize an institutionalized and scientific student cadre performance assessment system. In the meantime, the establishment of a scientific and effective student cadre performance assessment system may provide guidance and basis for the actual operation of student cadre work and play an active role in stimulating student cadres, perfecting and improving the construction of student cadres team.

\section{A. Type of Performance Assessment System}

Currently the internationally most famous scholars who conduct assessment on the performance are Borman and Motowidlo, which thought that the performance was divided into task performance contextual performance. [1] The task performance consists of activities which are directly related and behaviors of maintaining technical core. However, the contextual performance does not support the technical core of the organization, which supports a broader organization, social and psychological environment where the technical core is operated. The contextual performance has five types: first, willing to complete the work is out of the work scope of his or her own; second, able to successfully complete the tasks with excessive enthusiasm when necessary; third, to help and cooperate with others; fourth, able to follow the rules and

*Shandong Social Science Layout Research Project "Research on College Student Society Cadre Work Performance Assessment System" (15CSZJ39); 2. Shandong Technology and Business University Student Education Management Project Topic "Research on Student Cadre Work Performance Assessment System in Colleges” (2015XSZX015) procedures of the organization even when inconvenient; fifth, accept, support and protect the goals of the organization.

\section{B. About Performance Assessment on Governmental Officials and Enterprise Employees}

Performance assessment is an extremely important part in the performance management, yet the definition of performance assessment differs in the loop, for the administration, the performance assessment refers to "The government conducts assessment and estimation on the results of performance goals of the authorized under the principle of impersonality and justness" according to preset methods and standards... [2] for the enterprises, it refers to "According to mathematical statistics and operational research, through special indicator system and under the uniform assessment standards and certain procedures, quantitative and qualitative analysis are made to conduct impersonal, just and accurate estimation on the enterprise's economic benefits and operation achievements[3] In the opinion of A.Longsner, "The performance assessment is an organized and mater-of-fact assessment so as to clarify the employees' ability, working progress, adaptation and value to the organization, it consists of assessment procedures, standard and total methods." [4]

Seen from the above, we can draw a conclusion: the performance assessment is a formal employee assessment system, which adopts systematic methods and principles to assess and measure the employees' work conduct and results, based on, the HR management is instructed.

\section{On Student Cadre Assessment System}

First, three contents theory, the research thinks that main contents for the student cadre performance assessment in colleges mainly consist of basic quality (politics, morality and capability), work duty (moral education, backbone cultivation, routine management, study style construction, special student work, extra-curricular activity and innovative work) and work performance, in the course of specific operation, we can adopt score item or one-vote deny item. [5]

Second, four aspects theory, the student cadre assessment is mainly conducted from four points namely morality, capability, diligence and result. In the actual assessment, the four points must be subdivided into items operable and measurable. In the meantime, as for the weighing of morality, capability, diligence 
and result, morality and capability: $20 \%$ each, diligence: $10 \%$, result: $50 \%[6]$.

Third, five contents theory. Feb 2008, Shanghai Scientific and Technical Education Work Committee and Shanghai Educational Committee issued Opinions for Conducting Assessment on College Tutors in Shanghai, where the student cadre assessment indicators were uniformly released for the first time and the contents for student cadres assessment are stated at morality, capability, diligence, result and honesty, mainly including vocational concept, morality and politics education, construction of student organization, student affairs management, campus stability, featured and innovative work and so on.

Seen from the above, in recent years, the performance assessment theory has been widely used in governments and economic management to check and measure and assess the employees' work efficiency, attitude and results, which plays an important role in improving enterprises' economic benefits and organizational management level. Other social public sectors and colleges also start to explore efficient performance assessment modes to improve the work efficiency. He Shulian et al start to introduce the performance assessment methods to the student cadre assessment system for quantitative research. Therefore, to introduce the performance assessment to the student cadre work in colleges, set student cadre performance assessment concepts and build a scientific and rational work performance assessment system has become an important tasks for student supervisors.

\section{Connotation AND NeCESSity of StUdent CADRE ASSESSMENT IN COLLEGES}

In order to assess the work performance of a student cadre, we have to conduct an impersonal assessment on his or her work performance, which needs a scientific indicator system for assessment so as to reflect the actual performance of student cadres. The student cadre performance assessment system shall not only reflect the work performance and results of the student cadre within a given period, but also show what the student cadres do in the management and education. However, most contents relative to the student cadre work performance assessment are privacies, which are difficult to be quantified accurately, yet the performance assessment requires that all efficient quantitative data shall be got to reflect problems. Therefore, the student cadre performance assessment can be defined as: some work results quantitative which are shown in the actual work of student cadres through work efficiency, result quantity and work performance.

The 360-degree feedback assessment on student cadres in colleges will do good to form just work concepts and fine awareness of healthy competition. First, the 360-degree feedback assessment reflects the interaction between upper and lower, colleges, teachers and students, which itself increases and improve the exchanges between student cadres and other participants. Second, through the 360-degree feedback, student cadres may know the defects of their own, able to promote the professional development of the student cadres. Third, the assessment may promote the exchanges between student cadres, doing good to form sound team and cooperative atmosphere and strengthen the collective centripetal force.

\section{APPLICATION OF 3600-DEGREE FEEDBACK IN THE STUDENT CADRE PERFORMANCE ASSESSMENT}

\section{A. Design of Exam and Assessment Subject}

In order to reduce the errors arising out of the performance assessment as possible as well, according to the 360-degree feedback assessment method, the exam and assessment subjects here shall include upper of student cadres, workmates of student cadres, student cadres and students led by the student cadres. Thus the assessment has participants such as the superior, the same-level, the lower-level and themselves, and the integration of assessment opinions of student cadres in all aspects can impersonally reflect and quantify the work of student cadres. There are four parts totally, first, self assessment: student cadres shall assess what they have done, generally in the self assessment, they are tolerant to the work of their own, so it shall be kept in a lower proportion. Second, superior assessment: the superiors of student cadres' secondary schools will conduct assessment on the students' performance, which is the core of 360-degree feedback, so the part shall be kept in high proportion in weighing. Third, colleagues' assessment: generally the student work will need tens of students working together for frequent exchanges, and colleagues make more exchange among themselves, yet when they are in competition, the assessment may be not impersonal. Fourth, students' assessment: for student cadres, they are well known by students, especially the student cadres' work level, expression and work attitudes, so when assessing the student cadres, it is very necessary to invite student representatives to attend, which shall be kept in a higher proportion in weighing.

\section{B. Indicator system and Scoring}

The indicator system consists of four parts: morality (30 points: politics: 10 points, morality: 10 points, service: 10 points); capability (25 points: theoretical policy: 5 points, organizational skill: 5 points, innovation: 5 , analysis: 5 points, teamwork: 5 points); diligence (15 points: attendance: 5 points, work efficiency: 5 points, work attitude: 5 points); performance(30 points: class style: 10 points, study style: 10 points, special contribution: 10 points).

In addition, give impersonal points (minus or plus), for example, if the class and collectives led by student cadres get state-level awards, plus 6 points; if the class and collectives led by student cadres get provincial or ministerial award, plus 3 points; if the student in the class led by student cadres gets state-level award, plus 4 points; if the student in the class led by student cadres get provincial or ministerial award, plus 2 points; if more than 2 student work-related articles are released on $\mathrm{CN}$-level academic magazines, for every additional article, plus 2 points, if the student cadres get state-level award, plus 6 points, in case of provincial or ministerial award, plus 3 points and so on. 


\section{Calculation and Assessment of Points}

Take a student cadre as an example, at the annual assessment, the superior, workmate, himself/herself and students assessed with the average score as $90,85,90,85$. The total score is $90 \times 0.4+85 \times 0.2+90 \times 0.1+85 \times 0.3=85.5$. In addition, if he or she released three articles this year, his or her final score is $85.5+2=87.5$. In order to distinguish the student cadres, the final score can be quantified as excellent, better, good, pass, fail, 90 or more: excellent, 80-90: better, 70-80: good, 60-70: pass, 60 or less: fail, further, according to the assessment results, incentive measures will be taken.

\section{Design of Assessment Flow}

First, monthly assessment flow. First of all, according to the monthly work plan and completion of student cadres, the college will check and supervise them regularly or irregularly and make records. Second, within the first week of the next month, a monthly assessment sheet will be issued to student cadres who will assess the work of their own, then send it to the secondary college. Finally the college will make a monthly assessment according to the self assessment of student cadres and review of principals.

Second, annual assessment flow. First of all, a performance assessment sheet will be issued to student cadres at the end of a year. Second, student cadres shall make self assessment according to actual conditions, superiors, workmates, lower and students will quantify the student cadres before assessment Third, according to the assessment results, the college will adopt 360-degree feedback method to analyze the data according to weighing and finalize the annual performance assessment of student cadres. Finally with the student cadre performance assessment completed, the results will be submitted to the college performance assessment group for filing, which will be taken as basis for the next work arrangement.

\section{Possible Problems AND COUNTERMEASURES}

\section{A. Some of Student Cadres Refuse to Accept the Assessment System}

Educate and instruct student cadres to improve the fullmember management concept, it is well known that entire student cadres are standing on the same starting line, all the students shall bear responsibilities and be assessed in the performance assessment so as to make the performance assessment be really carried out and get effect.

\section{B. Non-unified Methods for Assessment}

Before the assessment starts, the college shall conduct specific training on assessors and the assessed, and the assessors shall fully understand the performance assessment and master the requirements and methods relative to the performance assessment of student cadres, besides, the assessed shall know relevant rules of assessment as well.

\section{Suggestion are Often Raised to Modify the Assessment System}

Though organizes spend more time and energy setting assessment indicators, yet more suggestions are raised in practice for modification, it is normal. The assessment organizers should know that the system setting and improvement is a circulating and improving process, only the system which meet actual conditions and attract wide suggestions can reflect the real benefits, so we must overcome the once and for all or eager-for-success thoughts.

\section{Assessment Results Are Used Only for Material Reward}

Material reward is an efficient stimulation to praise the excellent, yet which may cause student cadres to judge the superiors, workmates and students according to the reward, if the reward amount is kept unchanged, the student cadres will know where to solve problems and where to improve. The performance assessment may adopt material reward, yet it is just a part of the performance assessment, and the more important is make the student cadres know what their defects are so as to promote their work in the future.

\section{RESEARCH DIRECTION FOR THE FUTURE}

The theories of performance management in enterprises and governments and research results of student cadre assessment all provide us research thoughts and basis to borrow. However, when processing the research results, we must know that the work scope and positioning of college cadres still aim at students, and the performance assessment system will be new, multi-angle, all-sided and difficult.

Morality education shall insist on the human-oriented development direction. Grasp the social nature of human being, value rational needs of student cadres, focus on and realize the development level shall be point-cut for the human-oriented student cadre team management.

At present, the researches on lifelization and socialization of moral and political education are further deepened, and the performance assessment system of student cadre team that we need to establish must return to the life circle, which shall be made feasible in practice, it is a basic direction and important goal for the modern moral education.

\section{CONCLUSION}

In a word, when building a student cadre performance assessment system, first of all, we shall detail the work scope and requirements routine for student cadres, establish quantitative indicators suitable specific work and requirements according to the 360-degree performance assessment standard, then quantify and assess the student cadre performance so as to get a feedback result, at last, we will achieve the rating and assessment on the work in previous stage and lead, instruct and stimulate the work in the next stage. In the meantime, the student cadre performance assessment results shall be combined with incentive mechanism so as to keep the assessment system authoritative. Furthermore, during the implementation of performance assessment system, it must be kept standard and scientific and properly adjusted as the case may be so as to embody the core and nature of "humanized, 
human-oriented, efficient supervision and scientific management" to the maximum.

\section{REFERENCES}

[1] Wen Subin, Research on Enterprise Perforamnce Assessment on the Basis of Sustainable Development [M], Economic Science Press, 2011. pp121-122.

[2] Ma Guoxian, Government Performance Management, Fudan University Press, Ver. 2005, pp11-11.

[3] Statistics and Assessment Department; Ministry of Finance, Q\&A of Enterprise Performance Assessment, Economic Science Press, Ver. 2009, pp56-57.

[4] Fang Zhenbang, Performance Management, China Renmin University Press, Ver. 2013, pp34-35.

[5] Chen Ruisan, Hu Li'nan, Discussion on Significance, Contents and Methods of Student Cadre Job Performance Assessment, Journal of Shenyang Jianzhu University(Social Science), 2007(1).

[6] He Shulian, Thought of Improving Student Cadre Assessment in Colleges, Journal of Guangdong Communications Polytechnic, 2016(9). 